\title{
Transverse sinus dural arteriovenous fistula: a reversible cause of severe pulmonary hypertension in an extremely premature infant
}

\author{
Leah Jordan (10 , Nathan Rodgers, Kari D Roberts 두
}

Department of Pediatrics, University of Minnesota Medical Center, Minneapolis, Minnesota, USA

\section{Correspondence to Dr Leah Jordan; kraus685@umn.edu}

Accepted 28 January 202

\section{DESCRIPTION}

A male infant was born at $225 / 7$ weeks gestation with a birth weight of $520 \mathrm{~g}$. He developed rapidly progressing pulmonary hypertension $(\mathrm{PH})$ felt to be secondary to chronic lung disease of extreme prematurity. By 2 months of age, echocardiogram revealed moderate-severely depressed right ventricular (RV) systolic function and suprasystemic RV systolic pressure that did not improve despite maximal therapy with sildenafil, inhaled nitric oxide (iNO), bosentan, intravenous treprostinil, inhaled epoprostenol, milrinone and systemic steroids with dexamethasone and hydrocortisone. A trial of prostaglandin E2 to open the ductus arteriosus and relieve right-sided pressures was unsuccessful. He had frequent pulmonary hypertensive crises requiring maximum support and his prognosis for survival was grim.

The infant was on mechanical ventilation, furosemide and chlorothiazide, which were felt to be necessary secondary to chronic lung disease due to extreme prematurity rather than congestive heart failure. On day of life (DOL) 95 (42-week postmenstrual age (PMA)), cardiac catheterisation revealed suprasystemic mean pulmonary artery pressure $(65 \mathrm{~mm} \mathrm{Hg})$, high indexed pulmonary vascular resistance $\left(8.4\right.$ Woods units $\left.\times \mathrm{m}^{2}\right)$ and an exceedingly high superior vena cava (SVC) oxyhaemoglobin of $94 \%$ in the absence of partial anomalous pulmonary venous return, concerning for an

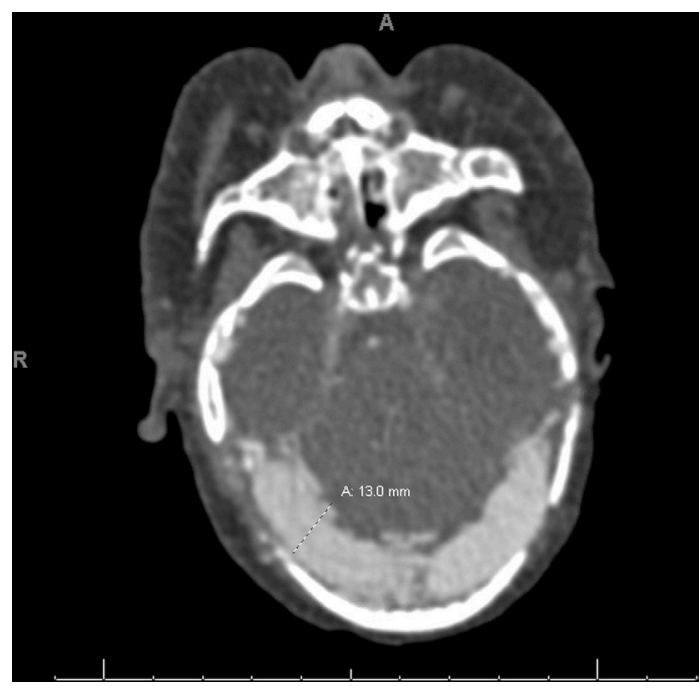

Figure $1 \mathrm{CT}$ of the head demonstrating 13-mm dilation of bilateral transverse and sigmoid sinuses extending to the jugular bulb.
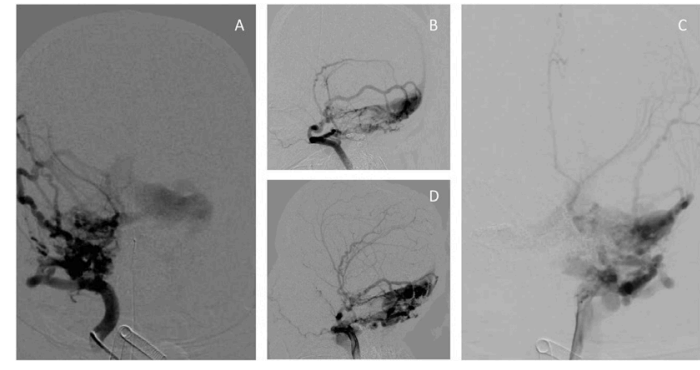

Figure 2 Baseline cerebral angiography (day of life 196) of the high flow dural arteriovenous fistula via the right carotid artery in anterior-posterior (AP) (A) and lateral $(B)$ projections and via the left carotid artery in AP (C) and lateral (D) projections.

arteriovenous malformation (AVM) of the head or neck. The finding of high SVC oxygen saturation was unexpected as multiple head ultrasounds throughout his neonatal intensive care unit (NICU) stay were negative for vein of Galen malformation and did not identify any other intracranial AVMs.

The patient was too clinically unstable to leave the NICU for further head imaging until DOL 190 (50-week PMA) when a CT scan of the head revealed bilateral distension of the dural sinus, sigmoid sinuses and jugular bulbs concerning for extensive arteriovenous anomaly (figure 1). Further evaluation with diagnostic cerebral angiography demonstrated a large, high flow transverse sinus dural arteriovenous fistula (DAVF) supplied by the bilateral external carotid arteries, internal carotid arteries and posterior meningeal branches (figure 2).

Over the next 36 weeks, the infant underwent five sequential endoscopic coiling and
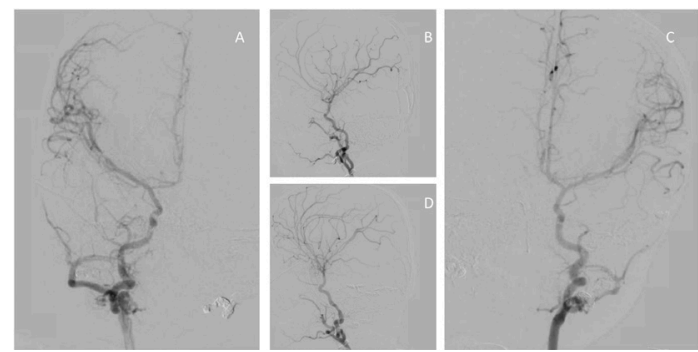

Figure 3 Cerebral angiography after complete obliteration of the dural arteriovenous fistula obtained via the right carotid artery in anterior-posterior (AP) (A) and lateral (B) projections and via the left carotid artery in AP (C) and lateral (D) projections. 


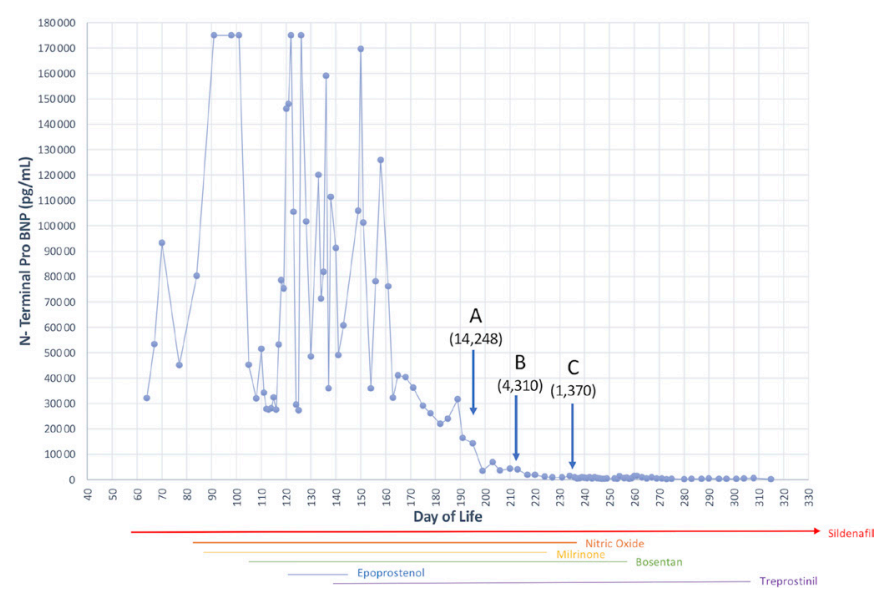

Figure $4 \mathrm{~N}$-terminal prohormone of brain naturetic peptide ( $\mathrm{N}$ terminal pro BNP) levels throughout hospitalisation. A, B and C mark the timing of the first three endovascular coiling procedures.

embolisation procedures resulting in complete occlusion of the DAVF (figure 3). These procedures were complicated by a brief hypoxic bradycardic arrest, thought to be respiratory in origin, and by a non-progressing and non-obstructive echogenic object in the RV extending into the right pulmonary artery, thought to be Onyx glue with thrombus or fibrin sheath formation. After embolisation, the infant had significant improvement in serial echocardiograms with RV systolic pressure decreased to less than one-half systemic pressure based on septal contour. N-terminal prohormone of brain naturetic peptide ( $\mathrm{N}$-terminal pro BNP) normalised and milrinone, bosentan, treprostinil, epoprostenol and iNO were successfully discontinued (figure 4). He was discharged home at 18 months of age on sildenafil and supplemental oxygen via tracheostomy.

On review of the infant's head ultrasounds, his transverse sinus was visualised via the transmastoid view with a size at the upper limit of normal for his gestational age. Doppler studies of the transverse sinus are not part of our institutional protocol for head ultrasounds and were not obtained given the size of his vessels were within normal limits.

Intracranial AVMs are a rare but well-described cause of $\mathrm{PH}$ in neonates. ${ }^{1}$ While vein of Galen malformations are more commonly associated with $\mathrm{PH}$ in this age group, DAVF account for approximately $5.7 \%-10 \%$ of all paediatric intracranial AVMs and have been described to cause $\mathrm{PH}$ in neonates. ${ }^{23}$ Unlike vein of Galen malformations, the natural history of DAVF presenting in the neonatal period is less well understood and may include spontaneous regression. ${ }^{45}$ This is the first reported case of a DAVF resulting in severe $\mathrm{PH}$ in an extremely premature infant with chronic lung disease of extreme prematurity and normal head ultrasound evaluations.

The most common sites of DAVF include the torcula, superior sagittal sinus, transverse sinus and cavernous sinus. ${ }^{2}$ Abnormalities in these deep structures may not be detected with traditional head ultrasound protocols. Thus, in neonates with disproportionately severe and/or rapidly progressing $\mathrm{PH}$, particularly those found to have elevated SVC oxyhaemoglobin on cardiac catheterisation, further evaluation for intracranial AVMs should be performed, even in the setting of a negative head ultrasound. Doppler images from the transmastoid view may help identify these deep DAVF when patients are too clinically unstable to obtain other imaging modalities.

Contributors $L J$ reviewed the case and prepared the manuscript for submission. KDR and NR edited the manuscript.

Funding The authors have not declared a specific grant for this research from any funding agency in the public, commercial or not-for-profit sectors.

Competing interests None declared.

Patient consent for publication Parental/guardian consent obtained.

Provenance and peer review Not commissioned; externally peer reviewed.

\section{ORCID iDs}

Leah Jordan http://orcid.org/0000-0002-5846-054X

Kari D Roberts http://orcid.org/0000-0002-8512-8729

\section{REFERENCES}

1 See AP, Orbach DB. Vein of Galen Arteriovenous Malformations. In: Primer on cerebrovascular diseases. Cambridge, MA: Academic Press, 2017: 482-7.

2 Hetts SW, Moftakhar P, Maluste N, et al. Pediatric intracranial dural arteriovenous fistulas: age-related differences in clinical features, angioarchitecture, and treatment outcomes. J Neurosurg Pediatr 2016;18:602-10.

3 Garcia-Monaco R, Rodesch G, Terbrugge K, et al. Multifocal dural arteriovenous shunts in children. Childs Nerv Syst 1991;7:425-31.

4 Lecce F, Robertson F, Rennie A, et al. Cross-Sectional study of a United Kingdom cohort of neonatal vein of Galen malformation. Ann Neurol 2018;84:547-55.

5 Maneenil G, Thatrimontrichai A, Janjindamai W, et al. Spontaneous regression of neonatal dural sinus malformation. Pediatr Int 2019;61:96-7.

\section{Learning points}

- In patients with severe and rapidly progressing pulmonary hypertension, evaluation for left-to-right shunts, including intracranial arteriovenous malformations (AVMs), should be performed.

- Abnormally high superior vena cava saturations on cardiac catheterisation should raise concern for intracranial AVMs.

- While vein of Galen malformations can often be identified with cranial ultrasounds alone, a negative head ultrasound does not rule out the possibility of other intracranial AVMs. Further imaging studies should be pursued if the index of suspicion remains high.

- Doppler studies from the transmastoid view may be a useful addition to head ultrasound protocols for the detection of deep intracranial AVMs, particularly for patients who are too clinically unstable to obtain other imaging modalities.

- Treatment of large intracranial AVMs may reverse the progression of pulmonary hypertension. 
Copyright 2021 BMJ Publishing Group. All rights reserved. For permission to reuse any of this content visit https://www.bmj.com/company/products-services/rights-and-licensing/permissions/

BMJ Case Report Fellows may re-use this article for personal use and teaching without any further permission.

Become a Fellow of BMJ Case Reports today and you can:

- Submit as many cases as you like

- Enjoy fast sympathetic peer review and rapid publication of accepted articles

Access all the published articles

Re-use any of the published material for personal use and teaching without further permission

Customer Service

If you have any further queries about your subscription, please contact our customer services team on +44 (0) 2071111105 or via email at support@bmj.com.

Visit casereports.bmj.com for more articles like this and to become a Fellow 